\title{
IDENTIFYING BEST-PRACTICE STRATEGIES FOR MANAGING RESIDENTIAL CAREGIVERS WORKING WITH CHILDREN AT RISK
}

\section{Anna Reznikovski-Kuras and Anna Gerasimenko}

\begin{abstract}
Residential caregivers are the central figures responsible for the children in their charge. Their work is physically and emotionally taxing, and carried out under pressure: they are prone to burnout. In addition, their status is lower than that of other staff. This study aimed to identify the strategies to improve caregiver functioning that have been adopted in Israel's residential social-service facilities, and to examine the extent of their implementation. A two-stage, mixed-methods study design was employed. In the qualitative stage, six successful care facilities were identified; their directors were interviewed in depth using the Learning from Success method. In the quantitative stage, a survey was administered to 95 directors, using open and closed questions. Six best-practice strategies for working with caregivers were identified: careful screening, training, ongoing supervision, personal and professional support mechanisms, flexible schedules, and a clear work plan and procedures. While these strategies were applied to some extent in most facilities, they varied in scope and implementation. Using a regression model, we found a connection between the implementation of these strategies and the directors' satisfaction with the caregivers' work. We discuss recommendations that can help directors incorporate the six strategies in residential homes and meet the challenges directors face in their work with caregivers.
\end{abstract}

Keywords: children at risk, out-of-home care, residential caregivers, learning from success

Anna Reznikovski-Kuras MA (corresponding author) is a Research Associate at Myers-JDCBrookdale Institute, POB 3886, 9103702 Jerusalem, Israel. Email: annare@jdc.org.il

Anna Gerasimenko MA is a Research Associate at Myers-JDC-Brookdale Institute, POB 3886, 9103702 Jerusalem, Israel. Email: annage@jdc.org.il 
Before you [the caregiver] go to meet your group of children, go to the mirror, and say: "These children were taken out of their homes because of (a), (b) and (c). Am I going to change things for them? Am I giving them something different? Because if I'm giving them more of the same, they would be better off with their parents. (Facility director)

The work here ... it's impossible to explain. Not what you have to cope with, not the feelings that the children bring out in you, and not how you come home after a day's work. No matter how people try to explain it to you, it doesn't come close to the real thing. (Residential caregiver)

From 2016 to 2018, at the request of the Israeli Ministry of Labor, Social Affairs and Social Services (MOLSA), the Myers-JDC-Brookdale Institute conducted a comprehensive study involving directors of residential care facilities in Israel (Ellenbogen-Frankovitz et al.,2018). This article is based on that research.

As we noted in Gerasimenko and Reznikovski-Kuras (2019), residential caregivers play a major role in the lives of children and adolescents ${ }^{1}$ in residential homes, with responsibility for their physical and emotional care and their educational needs (Baranes \& Bourdon, 1990; Ellenbogen-Frankovitz et al., 2018). To date, the professional status of residential caregivers in Israel has been undefined, and it has become clear that there is a need to identify best practices and methods for working with them. These can then be standardized for the purpose of upgrading the role and status of caregivers in all residential facilities in Israel. This article, which is part of a broader study on residential caregivers, focuses on identifying strategies directors can use for working with residential caregivers of children at risk and examines the extent to which those strategies have been implemented. The findings could serve as the basis for formulating theories and policies for further evolution of the caregiver role and continued professional upgrading.

\section{Characteristics of Residential Facilities for Children at Risk in Israel}

Out-of-home placements are necessary for many different reasons, ranging from environmental inadequacies that are impeding the child's optimal development, through physical and emotional neglect, to dangerous situations that pose a serious threat to the child's well-being or even their life (Zeira et al., 2012).

Out-of-home facilities utilize various models and methods of operation designed to adapt to the children's needs so that they will have the best chance of adjusting to life in the facility, and to rehabilitate and continue to grow and develop healthily. Israel stands out among the developed nations in its relatively large number of residential placements: in 2016 , a total of $7,168(72 \%)$ of

\footnotetext{
${ }^{1}$ Hereafter, we refer to children and adolescents as "children".
} 
all children at risk in Israel were in residential facilities, with only $28 \%$ in foster care (Israel National Council for the Child, 2018). In many developed countries, the proportions are reversed or there is at worst an equal division between residential facilities and foster families (Ainsworth $\&$ Thoburn, 2014). The high rate of residential placements in Israel is partly due to historical and cultural circumstances. In the years following the establishment of the State of Israel in 1948, residential schools were associated with training youth for the realization of Zionist settlement; they were designed for youth from all population strata and considered by the public to be normative settings (Grupper, 2004). These days, additional reasons for the high placement rate in residential facilities include the serious shortage of foster families, the objections of the biological families to having their children placed in foster families, and the fact that the compensation provided for giving foster care to relatives is inadequate (Silman, 2014).

There are three categories ${ }^{2}$ of residential facility in Israel, based on the severity of the children's needs. Educational and rehabilitative facilities serve those who, despite gaps in their schooling, learning difficulties, or emotional deficiencies, have the potential for normative development. Next on the continuum are therapeutic facilities, which serve children with organic, behavioral, and mental or emotional disorders that have led to deficient functioning in multiple areas, and who are in need of special education. In extreme cases, children who have come out of psychiatric hospitals or need an alternative to hospitalization are placed in post-hospital facilities (Dolev et al., 2009). ${ }^{3}$

Each residential care facility is affiliated with an educational stream: secular state education, state-religious education, Haredi (ultra-Orthodox) education, and Arabic-speaking education. The children have varying levels and types of difficulty, including learning difficulties; social, emotional, and behavioral problems (outbursts of anger, aggression, criminal behavior); and mental disturbances — some have been in psychiatric hospitals, and some have suicidal tendencies.

The subject of the care of children in residential facilities is, from time to time, the focus of public debate and criticism. In 2016, the State Comptroller (Ministry of Labor, Social Affairs, and Social Services, 2017) examined the process of placing children in residential facilities, what therapeutic and educational services were provided while they are there, and what was provided after their return to the community and in adulthood; they also reported on MOLSA's inspection and regulation of the facilities. The report found that the lack of clear policy from the Ministry with regard to the running of the facilities was detrimental to the care provided to the children and to the children's well-being. This gave rise to such problems as an absence of systematic information about the status of the children when they reach adulthood or about the effectiveness

\footnotetext{
${ }^{2}$ It is important to note that under the current reform of out-of-home placement, the categorization of residential facilities is likely to change.

${ }^{3}$ In addition to the residential facilities operated by MOLSA, the Ministry of Education operates educational residential facilities. These are for children with normative functioning or mild developmental disorders, and with high potential to improve their condition, and are not included in our study.
} 
International Journal of Child, Youth and Family Studies (2020) 11(4.2): 96-114

of work at the institutions to maintain their status; a lack of adequate investment in the students' scholastic advancement; and a lack of adequate preparation for adult life and support after age 18 (Ministry of Labor, Social Affairs, and Social Services, 2017).

In light of the changes that have taken place in recent years in the characteristics of children referred to out-of-home placement and the complexity of the challenges facing them both in Israel (MOLSA, 2018) and abroad (Budde et al., 2004; Dale et al., 2007), and, above all, public criticism, the Ministry appointed a committee to examine the care provided in residential facilities. The committee produced two documents, the aforementioned policy report (MOLSA, 2018) and a forthcoming book on procedures for operating residential facilities. The committee's work has led to the implementation of reforms in out-of-home placements, affecting a broad range of aspects of care in the facilities and working towards the formulation of policy that will meet the needs of the children and improve the services. This process includes a review of the role of caregiver in residential facilities.

\section{Complexity of the Role of Caregiver in Residential Facilities for Children at Risk}

Every type of residential facility for children at risk has a multidisciplinary professional therapy staff: social workers, psychiatrists, psychologists, and providers of various forms of therapy (e.g., art therapy). Alongside them works a team of educational professionals: residential caregivers, teachers, and housemothers (Dolev et al., 2009). In 2017, there were 1,600 care staff working with children in residential facilities under the supervision of MOLSA's Service for Children and Youth. Of these, approximately 900 were residential caregivers (Knesset, 2017).

These caregivers are crucial figures in the lives of each child at the facility: like their counterparts the world over, they are required to assume a "substitute parent" role and provide emotional support (Baranes \& Bourdon, 1990; White et al., 2009). At the same time, they are expected to help in the development of the children's talents, self-esteem, and independence, along with their interpersonal skills (Australian Youth Affairs Coalition, 2013; YouthLink Scotland, 2009). Over the years, the focus of the caregiver role has changed from social aspects to rehabilitation and caring for children by dealing with daily events (Cohen, 2000).

\section{Recruitment of Residential Caregivers}

In many European countries, candidates for the position of residential caregiver are required to be licensed to work with children at risk. Furthermore, during the recruitment process, the candidates go through a series of interviews, their recommendations from previous employers are checked, and they have to provide a certificate of good conduct from the police (United Kingdom Department for Education, 2011; Ireland Department of Health and Children, 2000). In the United States, most of the residential facilities require candidates to submit a drug test, to have a driver's licence, and to take a first-aid or resuscitation course. Preference is given to candidates with some prior experience of working with children (Bertolino \& Thompson, 1999). Studies have found that directors in residential care facilities look for caregivers whose personal qualities include 
International Journal of Child, Youth and Family Studies (2020) 11(4.2): 96-114

commitment and dedication to their work, emotional maturity, wisdom, and resilience as well as the knowledge and basic skills required to work with children (White et al., 2015). In Israel, there is no requirement for appropriate higher education or professional training. The majority of caregivers have no experience in the field, and most of them have just completed military service; in some cases, their work as caregivers is concurrent with university studies (Attar-Schwartz, 2010; Cohen \& Cohen, 2001; Talias \& Ben Yair, 2000).

\section{Difficulties at Work and with Burnout}

A number of studies (Barford \& Whelton, 2010; Shammai \& Moyal-Botwin, 2012; Talias \& Ben Yair, 2000) have identified working conditions that make it difficult for caregivers to do their job properly. One of the demands of the job is the requirement to be constantly available, which blurs the boundaries between professional and private life and creates an emotional burden. Even during what is officially their free time, caregivers have to be available to take phone calls and to respond to children's needs as they arise (Knesset, 2014). In their study of 94 child and youth care workers in a western Canadian city, Barford and Whelton (2010) noted that the most significant source of the pressure on caregivers is that they work with groups of children who are contending with a wide range of emotional and mental difficulties and who frequently exhibit antisocial behavior, including verbal aggression, self-harm, and refusal to accept treatment.

Working with this population can place severe strain on the emotional resources of caregivers. As reported by Talias and Ben Yair (2000), caregivers claimed that there is considerable disparity between the demands and expectations they face and the financial compensation they receive. Furthermore, they felt their status was regarded as inferior to that of other members of the professional staff and that they were therefore not sufficiently included in decision-making processes about the children and their future. Finally, the shift arrangements allowed little time for meetings with their fellow caregivers and they did not have professional contact with their colleagues at the facility (Talias \& Ben Yair, 2000).

In their extensive study of children's homes in the United Kingdom, Whittaker and colleagues (1998) found additional sources of pressure on caregivers: a lack of support from management, a feeling of powerlessness, and a negative impact on family life. A later study of caregivers in Israel by Shammai and Moyal-Botwin (2012) reported that the environment in which they worked subjected them to emotional, personal, and interpersonal pressures, and that their job was conflictual and overburdened, resulting in burnout. Burnout had a negative impact on the way caregivers dealt with tasks and challenges at work; many of them left the job within the first year.

\section{Professionalization of Residential Caregivers in Israel}

In Israel, as opposed to most European countries, the only basic requirement for the job of caregiver in a residential facility is 12 years of schooling: there is no legislation setting out the professional status of caregivers. Job requirements, conditions of employment, and career advancement prospects are all determined by the individual facility (Attar-Schwartz, 2010; Cohen 
International Journal of Child, Youth and Family Studies (2020) 11(4.2): 96-114

\& Cohen, 2001). To address this pattern of burnout and high turnover among caregivers, and ensure an appropriate level of care for children, it has been proposed in the literature to professionalize the role of the residential caregiver. In 2005, the international organization of social educators (Association Internationale des Educateurs de Jeunes Inadaptés - AIEJI) published the Montevideo Declaration (Regional Declaration on the New Orientations for Primary Health Care), which sets out demands for the licensing of social educators (equivalent to residential caregivers): they must receive pedagogical training equivalent to a bachelor's degree (i.e., graduation from university or college) and gain additional practical experience in order to be licensed for the job (Grupper \& Romi, 2015).

MOLSA current working procedures for training residential caregivers were presented at a meeting of the Knesset Committee for the Rights of the Child in May 2017. Currently, in addition to the basic training days provided by the Ministry, the training and study curriculum includes: an orientation period of several days after the caregivers have started working; workshops and seminars throughout the year, provided both by the facility and by MOLSA; social workers to provide support to the caregivers and all members of staff at the facilities; "educational guidance centers" providing guidance in all areas; and courses for caregivers once a year after they start working at the facility. The courses would be adapted for the general population, the Haredi population, and the Arab population (for whom they would be conducted in Arabic; Knesset, 2017).

\section{Study Design}

\section{Study Goal}

As noted above, residential caregivers play a crucial role in residential care facilities, but given their low professional status, they are frequently undervalued and underpaid, meaning that there are few professional promotion prospects, and high rates of burnout (Freeman, 2013; Knesset, 2014). This situation poses a great challenge to the facility directors in their efforts to recruit and retain caregivers. There are many suggestions in the literature about how to work with caregivers to enable them to give children the best care, as described in the Discussion section (below), while the current article reflects our efforts to produce a comprehensive paper with practical applications.

The goal of the study discussed here was to collect up-to-date information at residential facilities for children at risk in Israel regarding the strategies used by directors and professional staff in their work with caregivers, and use that information to identify best-practice strategies and examine whether there is a connection between the extent that such strategies are implemented and the directors' satisfaction with the caregivers' work.

\section{Study Method}

This was a mixed-methods study conducted in two stages. The first stage of the study used a qualitative method in which specific and effective strategies for evolving the caregiver role were 
International Journal of Child, Youth and Family Studies (2020) 11(4.2): 96-114

identified and conceptualized. The second stage used a quantitative method, in which measures for mapping the strategies were devised and a survey of facility directors was conducted to examine their applicability.

\section{Study Population}

Stage 1: National inspectors at MOLSA selected six residential facilities that they judged to be working successfully with caregivers. The success measures included: job retention, optimum performance, caregivers' satisfaction with the work, and professional staff's satisfaction with the caregivers. The directors of these six facilities were interviewed.

Stage 2: Residential care facilities in Israel are of three kinds: therapeutic (51\%), rehabilitative or rehabilitative-therapeutic $(28 \%)$, and post-hospital or post-hospital therapeutic $(21 \%)$. The directors who participated had held their positions for an average of 8 years $(8-38$ years; $S D=$ 8.1). Their educational backgrounds were in the fields of education and special education, social work, psychology, criminology, and management. A slight majority (56\%) held a master's degree or a doctorate; $35 \%$ had a bachelor's degree.

\section{Research Tools and Data Collection}

Stage 1: The interviews at the selected facilities were based on the Learning from Success method, in the belief that systematic learning from the past and the use of principles that have already proved successful could be a good foundation for similar outcomes, provide leverage for assimilation of collective learning in an organization, and lead to improvement of products in the future (Sykes et al., 2006).

The Learning from Success method is based on 10 stages of research (Sykes et al., 2006): (a) describing the organizational context; (b) identifying a success worthy of being learned, and defining the field of success; (c) concisely describing the success in terms of "before" and "after"; (d) identifying positive outcomes of the success — both objective and subjective; (e) identifying any negative "side effects" or costs of the success; (f) examining whether the success indeed justifies further learning; (g) detailing the actions that led to the success; (h) identifying turning points between "before" and "after"; (i) deriving the common elements that underlay the actions that led to the success; and (j) identifying unresolved issues for further learning.

Based on these 10 stages, specially trained interviewers conducted preliminary interviews with the directors of facilities that had had notable success in their work with caregivers. The purpose of the questions was to enable us to identify, reveal, and conceptualize the professional knowledge that until then had been implicit only, and turn it into explicit, actionable knowledge. The interviews took place from November 2016 through February 2017. From the interviews, six strategies that the directors considered to be successful were identified.

Stage 2: The directors of all residential facilities under MOLSA's responsibility were surveyed to determine which of the six strategies for optimum work they used in working with caregivers. 
In order to collect the data, we built a self-report internet survey. Before sending it out, we conducted a pre-test of all the questions with three directors. In light of their feedback, the questionnaire was then revised and unclear or irrelevant items were deleted. It was then distributed to the directors of MOLSA's residential care facilities throughout Israel to be completed anonymously. The data were collected in the summer of 2017. Of the 95 directors who received questionnaires, $75(79 \%)$ responded.

The extent to which each strategy was implemented was examined quantitatively using questions suitably formulated for each strategy. For example, regarding the first strategy identification of quality caregivers with suitable skills by means of thorough screening — the directors were asked about the number of interviews conducted with each candidate, and about the length of the recruitment process (one or two days, about a week, two weeks, about a month). The directors' satisfaction with the caregivers' work was examined with a general question, "How satisfied are you with the caregiver's work?", and with more focused questions about different aspects of their work, such as: concern for the well-being of the children; ability to manage a group of children, cope with violence or behavioral problems, and provide the children with emotional support; their relationship with the school and with parents; and so on.

\section{Data Analysis}

Stage 1: The quantitative analysis of the six interviews was conducted using the thematic approach (Braun \& Clarke, 2006), and comprised several steps. Firstly, the researchers read the interviews several times to identify subjects for analysis. The subjects identified were divided into text units with significant meaning. These were then grouped by central themes that recurred in several interviews and then grouped by strategy. Finally, these strategies were defined and given titles covering all the contents of each. For example, "creating mechanisms for personal and professional support of the caregiver" included components such as giving positive reinforcement to the caregivers, fostering a personal connection between the directors and the caregivers, showing great professional appreciation to the caregivers, and recognizing the importance of their role and the therapeutic value of their work.

Stage 2: The SPSS program version 24 was used to analyze the data. In order to determine whether implementation of the strategies considered successful by the respondents was correlated with their satisfaction with various aspects of the caregivers' work, an "implementation of strategy measure" was calculated for each facility included in the survey. The measure summarized the extent to which each strategy was implemented, making it possible to attribute them to a single factor, thereby simplifying the analysis. A dichotomy summary score was calculated for each strategy, after which a summary measure was calculated, indicating the number of strategies implemented. The average measure was $3.19(S D=1.63$, range: $0-6)$. Exploratory factor analysis was conducted with Varimax rotation, accounting for $59.9 \%$ of the variance.

The analysis conducted for questions relating to the responding directors' satisfaction with the caregivers' work produced two separate summary measures, one regarding caregivers' 
International Journal of Child, Youth and Family Studies (2020) 11(4.2): 96-114

performance in the emotional and social area (Cronbach's alpha .871) and the second regarding their performance in the scholastic area and their relationship with the parents (Cronbach's alpha .669). We then conducted a linear regression to examine the impact of the type of facility, and the extent to which the strategies were implemented, on the directors' satisfaction with the caregivers' work.

\section{Findings}

The study findings are presented in two stages. First, we present the six best-practice strategies for working with the caregivers and the statistics regarding the extent to which each is implemented in residential facilities in Israel. Next, we present an examination of the correlation between the responding directors' satisfaction with caregivers' work and implementation of the strategies at the facilities. This demonstrated that these strategies are indeed optimal and result in good performance by the caregivers and optimal care of the children.

\section{Description of the Strategies and Extent of Implementation}

The following six strategies for working with residential caregivers were identified and recommended:

- Identifying quality caregivers with the right skills by thorough screening of candidates;

- Providing successful candidates with training (both immediately upon assuming their role and in the course of their work);

- Providing them with ongoing supervision;

- Creating mechanisms for personal and professional support, such as positive reinforcement, promoting good relations with the director, supporting caregivers as far as possible when they make mistakes, and constantly ensuring all is well with them;

- Creating working arrangements that take their individual needs into consideration and offering incentives; and

- Formulating clear work plans and procedures.

In the following paragraphs, we describe in greater detail each of the recommended strategies for the evolution of the role of residential caregiver and our findings about the extent of their implementation in residential facilities.

\section{Strategy 1: Identifying Quality Caregivers with the Right Skills Through a Thorough Screening Process}

In the past, anyone with a birth certificate living nearby the facility could get work here as a caregiver. Nowadays, caregivers are chosen with a fine tooth comb. (Facility director) 
International Journal of Child, Youth and Family Studies (2020) 11(4.2): 96-114

For the selection process, the directors set entrance requirements for candidates, such as: completion of military, civic, or national service; relevant training in the field of education or therapy (psychology or social work); experience working with children; experience of command in the army or counselling in a youth movement; sense of mission and a wish to contribute; rich language skills; willingness to learn; interpersonal abilities; and personal resilience.

In most of the facilities that responded to the survey, the process of recruiting candidates prior to their acceptance as caregivers lasted between 2 weeks and a month (75\%). During that time, in most of the facilities (85\%), each candidate underwent at least two interviews, in which they were told what the job involved and were informed about the characteristics and status of the children. In most cases $(88 \%)$, the interview was conducted by the director of the facility; the caregiver coordinator and a social worker were often involved as well. Apart from the interviews, the recruitment process included other components, such as a review of recommendations from previous employers; tests (personal compatibility test, polygraph or graphology test, or participation in a group dynamic); and observation and hands-on experience (observation of a group activity and sometimes working alongside experienced caregivers).

\section{Strategy 2: Providing Professional Training Immediately upon Assuming Their Role and in the Course of Their Work}

We carry out training, then more training, then yet more training. (Facility director)

Professional training was provided to the caregivers when they started work and periodically during the course of their employment. The training sessions were conducted in large groups and addressed cross-cutting professional issues affecting the work in the residential facilities, such as the educational philosophy at the facility, what it means to be a new caregiver, the role of caregiver, the characteristics of the child population, the basic principles of caring, the history of the facility, the daily schedule in the facility (e.g., wake-up, breakfast, homework, lights-out), and establishing authority - a mainly theoretical element that also includes self-examination and identification of a personal authoritative style.

Most of the responding directors (92\%) reported that all of the caregivers participated in all of the training sessions given by the facilities. Nearly as many (84\%) considered that the training contributed to a great or very great extent to the caregivers' ability to perform their work. However, the directors noted areas that should be added or strengthened: a precise definition of the role, and the meaning and importance of caregivers; work procedures for caregivers (relationships, monitoring and reporting, time management); and the language and practice of educational and therapeutic work with children at risk.

\section{Strategy 3: Providing Regular and Ongoing Supervision to the Caregivers}

The supervision meetings are the place to talk, to dwell on dilemmas, mainly to diffuse distress, aggression, and depression. Without this embrace, people wouldn't be able to carry on. (Facility director) 
International Journal of Child, Youth and Family Studies (2020) 11(4.2): 96-114

The supervision meetings were held regularly at the responding facilities, led mainly by the social worker (87\%) and sometimes by other professionals (e.g., the caregiver coordinator, psychologist, or facility director). Supervision meetings are another way of training caregivers for their work and were provided to every caregiver as needed, whether individually, in pairs, or in small groups.

Every responding facility ensured that caregivers participated in the supervision meetings; 89\% of the directors reported that all the caregivers in the facilities for which they were responsible received ongoing supervision, in most cases $(66 \%)$ one or more times a week. The supervision meetings addressed the daily work of the caregivers, questions and challenges that needed to be resolved (e.g., how to keep a stressed child occupied; how to talk to him or her; how to recognize when the child is about to explode); and provided emotional support when needed.

\section{Strategy 4: Creating Mechanisms for Personal and Professional Support}

The most important thing, just like for the children, is for the caregivers to feel embraced, included, and strengthened. That they have backing and someone [standing] beside them. (Facility director)

Most of the directors interviewed in the preliminary stage attributed great importance to personal and professional support and provided it in various ways. Personal support was given through positive reinforcement within a framework of strict adherence to the facilities' rules and regulations; fostering a personal relationship between the director and the caregivers; and sending the caregivers a clear message that they did not have to cope on their own, that there was always someone to talk to, and that help was always available. Professional support comprises practices such as professional fostering of the caregivers and constant concern for their well-being; showing professional appreciation, and recognizing the importance of their role and the therapeutic value of their work; giving backing, as far as possible, to those who made mistakes; and communicating to them that they were expected to share their difficulties and challenges with other members of staff.

Another way to support the caregivers over time was to develop new roles for them, based on needs in the field, that allowed for interest and personal development. Such roles were aimed at reducing burnout and facilitating personal development, variety, and interest. In $40 \%$ of the responding facilities, the directors reported that caregivers had additional roles: in the area of recreation (e.g., responsibility for events and field trips, volunteer coordinator, sports coordinator); responsibilities for staff members (e.g., for night-shift caregivers and other caregivers, mentoring for new caregivers); educational roles (e.g., study coordinator, liaison with the school, responsibility for tutoring); and other tasks (transport coordinator, security coordinator, medical coordinator). 
International Journal of Child, Youth and Family Studies (2020) 11(4.2): 96-114

\section{Strategy 5: Creating Working Arrangements that Take Account of Caregivers' Individual Needs and Providing Incentives}

We've learned that a 100 percent full-time position is too much. It doesn't allow for family life or couple relationships, so our caregivers work in less than full time positions. (Facility director)

The responding facility directors were aware of the possibility of burnout due to the intensity and pressure of the caregivers' work. In order to prevent burnout, the caregivers were allowed flexible hours that suited their needs and preferences. They were invited to events at the facility (parties, field trips), and staff days and fun days were arranged for them.

Another way of rewarding the caregivers was to provide incentives having financial value or offer the opportunity for professional advancement. A majority of the directors (58\%) offered at least one form of incentive (out of four proposed) as a reward for the caregivers: housing at the facility, better salary conditions, a scholarship for higher education, and a grant for a non-degree course. The most common form of incentive was housing at the facility, which was offered in $40 \%$ of the facilities, followed by better pay (25\%), and scholarships for higher education (20\%).

\section{Strategy 6: Formulating Clear Work Plans and Procedures}

We have clear plans and there are things that both the caregivers and I are allowed to do - exactly the same things. The caregiver will get wholehearted backing from me if he responds correctly, in exactly the same way as I would respond in the same situation. (Facility director)

A key factor in caregivers' success is based on the tools available to them when they work with the children. The directors emphasized that a uniform approach to the children made the staff's work easier and had greater success. To this end, the directors noted the importance of having the caregivers follow orderly procedures and work methods: all responding directors (100\%) endorsed the use of standardized professional language for all the staff at the facility, including a system of rules to impose uniformity in reacting to irregular behaviors; 97\% provided clear instructions to the caregivers regarding work practices at the facility, thereby reducing uncertainty about what to do and increasing the likelihood that work would be conducted in accordance with the facility's vision; and 94\% provided ongoing information about the children and regular contact with the professionals taking care of them.

\section{Correlation Between Directors' Satisfaction with Caregivers' Work and Implementation of the Strategies}

A factor analysis of 10 questions about the responding directors' satisfaction with various aspects of caregivers' work produced two factors. The first, "direct work with the children", included most of the social and emotional aspects of the caregivers' work: the work in general, their attitudes towards the needs of each child, their concern for the well-being of the children, and their ability to manage groups of children, to cope with violence and behavioral problems, to 
organize recreational activities, and to provide emotional support to the children. The second factor, "scholastic assistance and relationship with parents" included questions about the relationship with the school, the scholastic assistance provided, and the caregivers' relationship with the parents of the children.

In order to examine the correlation between the extent that the strategies for optimum work were implemented with the caregivers, and the characteristics of the facilities and the directors' satisfaction with the caregivers, we conducted linear regressions that included the type of facility and the extent of implementation of the strategies as explanatory (independent) variables, and the two factors of the directors' satisfaction as explained (dependent) variables. The outcomes of the first regression are presented in Table 1. Using the proposed model, it is possible to predict the directors' satisfaction with the first factor, caregivers' direct work with the children. After controlling for the type of facility, the extent of implementation was found to correlate positively with the directors' satisfaction with caregivers' direct work with the children.

In contrast, it was not possible to predict the directors' satisfaction with the second factor, scholastic help given by the caregivers to the children and their relationship with parents. In further examinations, no significant correlation between the directors' demographic characteristics (education and tenure) and their satisfaction with the caregivers was found.

Table 1. Linear Regression Model to Predict Directors'Satisfaction with Caregivers' Direct Work with Children (Factor 1) by Implementation of Strategies and by Facility Characteristics

\begin{tabular}{lcccc}
\hline Explanatory variable & $B$ & $S E(B)$ & $\beta$ & $t$ \\
\hline Type of facility & .115 & .096 & .139 & 1.195 \\
Extent of implementation & .100 & .042 & .273 & $2.349^{*}$ \\
$R^{2}$ & .088 & & & \\
$F$ & $3.299^{*}$ & & & \\
\hline
\end{tabular}

Note: $n=70$ (only 70 of the 75 directors interviewed responded to all the questions in this model). $* p<.05$.

\section{Conclusion}

This study on supervision and training for staff caring for children from at-risk situations was designed to benefit caregivers working in residential facilities for children and youth. Given the centrality of the caregivers' role and the high rates of burnout and turnover, the study goal was to create a foundation on which to formulate policy and strategies to further evolve the role of caregiver and continue to upgrade it professionally. While the study was conducted in facilities belonging to MOLSA, the insights from it could be relevant for caregivers in other Israeli residential facilities, such as those operated by the Ministry of Education.

What makes this study special is the methodology. The Learning from Success method was used for interviews in the first (qualitative) stage, and identified six effective strategies for evolving 
International Journal of Child, Youth and Family Studies (2020) 11(4.2): 96-114

the role of residential caregiver. The identified strategies were then used in the second (quantitative) stage, which surveyed directors of all residential facilities under MOLSA's responsibility in order to examine the feasibility of the strategies at the national level and validate their importance regarding the directors' satisfaction with various aspects of the caregivers' work. The response rate to the survey was $79 \%(n=75)$. Findings revealed that although the strategies were implemented in most of the facilities, there was variance among them in the extent and method of implementation.

With their first-hand knowledge of the complex role of residential caregivers on the one hand and of the needs of the facility on the other, directors constitute a reliable professional source and make a vital contribution to this discussion. The two factors impacting the directors' satisfaction with caregivers are caregivers' direct work with the children, and caregivers' provision of scholastic assistance to the children and their relationship with the parents. We found that the more extensive the implementation of the six strategies, the greater was the directors' satisfaction with the caregivers' direct work with the children. However, the degree of implementation did not correlate with the directors' satisfaction regarding the provision of scholastic help and the relationship with parents. This finding could possibly mean that there is a need to invest in training and supervision strategies to enable the caregivers to respond to scholastic needs and develop their relationship with parents using the relevant tools and skills (as proposed in the State Comptroller's report; Ministry of Labor, Social Affairs, and Social Services, 2017).

There is much discussion in the literature about the importance of investing in the nonprofessional staff at residential facilities, so that they can adapt their care according to the particular needs of each child in the best possible way, and so that their work with the children will produce the desired results. Most of the six strategies found in the current study have also been mentioned in the research literature and in discussions in professional and public forums, as follows:

1. Careful selection of caregivers so as to recruit quality personnel suited for the job (Leichtman, 2006) can be achieved by establishing licensing rules for working in residential facilities (Department of Health and Children, 2000; Department for Education, 2011). Under such rules (not yet in effect in Israel), the candidates' personal characteristics, education, professional experience, and affinity for working with children must be suitable before they are accepted for the job (Bertolino \& Thompson, 1999; Kashti et al., 2008; White et al., 2015).

2. Providing comprehensive training and (3) Providing ongoing supervision for caregivers working on therapy and rehabilitation with the children is necessary (White et al., 2015), given that therapy for children at risk cannot rely solely on personal characteristics and natural instincts (Cohen \& Cohen, 2001; Freeman, 2013; Kashti et al., 2008; Leichtman, 2006; Zemach-Marom et al., 2012). 
International Journal of Child, Youth and Family Studies (2020) 11(4.2): 96-114

4. Creating mechanisms to support the caregivers has been suggested by Leichtman (2006) and Whittaker et al. (1998).

5. Working arrangements that meet caregivers' needs and the provision of incentives are necessary in view of the physically and emotionally demanding nature of the work (Barford \& Whelton, 2010; Shammai \& Moyal-Botwin, 2012). One way to use incentives to retain caregivers and prevent burnout would be to develop an advancement track and scholarships for higher education (Knesset, 2014; Talias \& Ben Yair, 2000).

6. Clear work procedures, along with making the caregivers partners in the theoretical concept by which the facility works, are key to caregivers' success (Leichtman, 2006).

\section{Limitations of the Study}

In the current study, we collected data from the directors of residential facilities and no other sources. To obtain a more complete picture, we recommend that follow-up studies examine attitudes from additional perspectives, such as those of the caregivers themselves, who can provide unique insights through their own assessment of their professional performance and best practices for improving their work; and those of staff members of MOLSA, who have a broad overview of all the residential facilities, know how each of them operates, and have information about the status of the children.

We were able to reach only limited conclusions about the effectiveness of the strategies. The current study examined the extent to which Israel's residential care facilities had implemented the strategies, but not the extent to which the difficulties experienced by caregivers in their work (emotional burden, physical burnout) had been impacted. Follow-up studies should examine the impact of each of the strategies identified in the current study on reducing or preventing such difficulties.

\section{Implications and Recommendations for Practice and Policy}

This study gives rise to a number of recommendations whose implementation would allow directors of residential facilities to better contend with the challenges they face in their work with caregivers. Many directors spoke of the difficulty of recruiting caregivers with the right skills. To address this, we recommend joint action by MOLSA and other key organizations working in the field (e.g., nonprofit organizations) to ensure that caregivers receive training before they start work and to advertise jobs in such a way that suitable candidates can be found and referred to the facilities.

In order to provide sufficient pre-employment basic training to caregivers, we propose increasing access to the training programs already provided by MOLSA, perhaps by opening several training cycles each year, with suitable remuneration for those who participate. In addition, 
we recommend that assistance be given to the facilities to conduct in-house training; for example, by setting guidelines for the contents of the training.

Finally, we propose capitalizing on the knowledge and experience that has accumulated at those facilities where the work with the caregivers is considered successful. For example, several directors have established a relationship between their facility and a college such that time spent by caregivers participating in courses relevant to their specialization or practical work is compensated as employment. Enabling mutual learning among residential facilities could lead to wider adoption of best-practice strategies such as those identified in this paper. 
International Journal of Child, Youth and Family Studies (2020) 11(4.2): 96-114

\section{References}

Ainsworth, F., \& Thoburn, J. (2014). An exploration of the differential usage of residential childcare across national boundaries. International Journal of Social Welfare, 23(1), 16-24. doi:10.1111/ijsw.12025

Attar-Schwartz, S. (2010). The emotional-behavioral functioning of children at rehabilitative and therapeutic residential facilities: Contribution of personal characteristics, institutional characteristics and characteristics of the social climate. [Summary report to the Ministry of Social Affairs; in Hebrew]. Hebrew University.

Australian Youth Affairs Coalition. (2013). The AYAC definition of youth work in Australia. http://www.ayac.org.au/uploads/131219 Youth Work Definition FINAL.pdf

Baranes, F. H., \& Bourdon, L. (1990). Cross-cultural perspectives in residential youth-work: The French educateur and the American child care worker. Child and Youth Services, 13, 301315. doi:10.1300/J024v13n02_10

Barford, S. W., \& Whelton, W. J. (2010). Understanding burnout in child and youth care workers. Child \& Youth Care Forum, 39, 271-287. doi:10.1007/s10566-010-9104-8

Bertolino, B., \& Thompson, K. (1999). The residential youth care worker in action: A collaborative, competency-based approach. Haworth Mental Health Press.

Braun, V., \& Clarke, V. (2006). Using thematic analysis in psychology. Qualitative Research in Psychology, 3, 77-101. doi:10.1191/1478088706qp063oa

Budde, S., Mayer, S., Zinn, A., Lippold, M. A., Avrushin, A., Bromberg, A., Goerge, R., \& Courtney, M. E. (2004). Residential care in Illinois: Trends and alternatives [Final report]. Chapin Hall Center for Children at the University of Chicago.

Cohen, A., \& Cohen A. (2001). Report of the findings and recommendations for strategies in the framework of a policy study on "Professionalization of educational-social work in Israel," Part 1 [Consultative study; in Hebrew]. Research and Consulting.

Cohen, H. (2000). Residential caregiver - Profession or occupation? [In Hebrew]. Efshar, 7(5).

Dale, N., Baker, A. J. L., Anastasio, E., \& Purcell, J. (2007). Characteristics of children in residential treatment in New York state. Child Welfare, 86 (1), 5-27.

Dolev, T., Ben-Rabi, D., \& Zemach-Marom, T. (2009). Residential care for children "at risk" in Israel. In M. E. Courtney \& D. Iwaniec (Eds.), Residential care of children: Comparative perspectives (pp. 72-88). Oxford. doi:10.1093/acprof:oso/9780195309188.003.0005 
International Journal of Child, Youth and Family Studies (2020) 11(4.2): 96-114

Ellenbogen-Frankovitz, S., Navot, M., Reznikovski-Kuras, A., Gerasimenko, A., Aizik, I., \& Ben-Rabi, D. (2018). Boarding-school counselors for at risk children in Israel: Situation report and strategies to cope with the challenges of their work [in Hebrew]. Myers-JDCBrookdale Institute. Executive summary in English at https://brookdale.jdc.org.il/wpcontent/uploads/2018/05/Eng_summary_775_18.updated.pdf

Freeman, J. (2013). The field of child and youth care: Are we there yet? Child \& Youth Services, 34(2), 100-111.doi:10.1080/0145935X.2013.785875

Gerasimenko, A., \& Reznikovski-Kuras, A. (2019). Attitudes of residential care facility directors towards the need for professional accreditation and licensing of caregivers. Institutionalised Children Explorations and Beyond, 6(2), 174-184. doi:10.5958/2349-3011.2019.00019.7

Grupper, E. (2004). Boarding schools in Israel: Original creation of the Ministry of Education. In S. Shammai (Ed.), Residential education in Israel [In Hebrew]. The Educational Center, Administration of Rural Education, and Youth Aliyah.

Grupper, E., \& Romi, S. (2015). Questions of training for the role of educational-therapeutic workers. In E. Grupper and S. Romi (Eds.), Children and adolescents in risk situations in Israel (Vol. 2, pp. 329-350; in Hebrew). Mofet Institute.

Ireland Department of Health and Children. (2000). National standards for children's residential centres. Brunswick.

Israel National Council for the Child. (2018). NCC statistical yearbook [In Hebrew]. Israel National Council for the Child, Research and Development Center.

Kashti. Y., Grupper, E., \& Shleski, S. (2008). Residential education towards the next decade: Report of the Residential Education Planning and Development Committee [In Hebrew]. Ministry of Education.

Knesset. (2014). Defining the role of the caregiver in out-of-home frameworks [Minutes of the discussion in the Committee for the Rights of the Child, February 20, 2014; in Hebrew].

Knesset. (2017). Training of caregivers employed in residential facilities of the Ministry of Social Affairs and Services and the Ministry of Education [Minutes of a discussion in the Committee for the Rights of the Child, May 16, 2017; in Hebrew].

Leichtman, M. (2006). Residential treatment of children and adolescents: Past, present, and future. American Journal of Orthopsychiatry, 76(3), 285-294. doi:10.1037/0002$\underline{9432.76 .3 .285}$

Ministry of Labor, Social Affairs, and Social Services. (2017). Annual report 67b: Children and youth at risk in residential facilities of MOLSA (pp. 719-761; in Hebrew). 
International Journal of Child, Youth and Family Studies (2020) 11(4.2): 96-114

Ministry of Labor, Social Affairs, and Social Services. (2018). Policy of residential facilities for children and youth, 2018 (in Hebrew).

Shammai, S., \& Moyal-Botwin, M. (2012). The need for a protection patrol for caregivers: Follow-Up of adjustment of residential direct educators in their first year at general residential facilities [In Hebrew]. Ministry of Education.

Silman, Y. (2014). Report of the committee examining the Ministry's policy on out-of-home placements for children and visitation rights [In Hebrew]. Ministry of Social Affairs and Services.

Sykes, I., Rosenfeld, J., \& Weiss, T. (2006). Learning from Success as leverage for school-wide learning: A pilot program - 2002-2005. The first method: Learning from past successes - the retrospective method [In Hebrew]. Myers-JDC-Brookdale Institute.

Talias, M., \& Ben Yair, S. (2000). Developing a comprehensive model for the management of residential caregivers in facilities of the Service for Children and Youth [In Hebrew]. Elkathe Institute for Leadership and Governance.

United Kingdom Department for Education. (2011). Children's homes: National minimum standards. Crown Copyright.

White, R. D., Omelczuk, S., \& Underwood, R. (2009). Defining the nature of youth work. In R. D. White (Ed.), Concepts \& methods of youth work (pp. 7-18). Australian Clearinghouse for Youth Studies.

White, C., Gibb, J., Graham, B., Thornton, A., Hingley, S., \& Mortimer, E. (2015). Training and developing staff in children's homes. Department for Education.

https://www.ncb.org.uk/sites/default/files/uploads/documents/Research_reports/Training_dev eloping_staff_childrens_homes_summary.pdf

Whittaker, D., Archer, L., \& Hicks, L. (1998). Working in children's homes: Challenges and complexities. Wiley.

YouthLink Scotland. (2009). Statement on the nature and purpose of youth work. https://www.youthlinkscotland.org/media/1255/statementonthenatureandpurposeofyouthwork. pdf

Zeira, A., Attar-Schwartz, S., \& Benvenisti, R. (2012). Children and youth in out-of-home placements in Israel: Issues and challenges [In Hebrew]. Mifgash-Journal of Social Educational Work, 36, 9-16.

Zemach-Marom, T., Halaban-Eilat, H., \& Szabo-Lael, R. (2012). Number and characteristics of children in residential facilities: Trends from 2000-2010 [In Hebrew]. Mifgash-Journal of Social Educational Work, 36 (2), 17-38. 